University of Nebraska - Lincoln

DigitalCommons@University of Nebraska - Lincoln

\title{
Analysis Of Partially Electroded Piezoelectric Actuators With Nonuniform Thickness For The Purpose Of Reducing Actuating Shear Stress Concentration By Ansys
}

Nan Liu

University of Nebraska-Lincoln, nliu1@unl.edu

Hongping $\mathrm{Hu}$

Huazhong University of Science and Technology, hphu@yahoo.cn

Follow this and additional works at: https://digitalcommons.unl.edu/mechengfacpub

Part of the Mechanical Engineering Commons

Liu, Nan and Hu, Hongping, "Analysis Of Partially Electroded Piezoelectric Actuators With Nonuniform Thickness For The Purpose Of Reducing Actuating Shear Stress Concentration By Ansys" (2011). Mechanical \& Materials Engineering Faculty Publications. 71.

https://digitalcommons.unl.edu/mechengfacpub/71

This Article is brought to you for free and open access by the Mechanical \& Materials Engineering, Department of at DigitalCommons@University of Nebraska - Lincoln. It has been accepted for inclusion in Mechanical \& Materials Engineering Faculty Publications by an authorized administrator of DigitalCommons@University of Nebraska Lincoln. 


\title{
ANALYSIS OF PARTIALLY ELECTRODED PIEZOELECTRIC ACTUATORS WITH NONUNIFORM THICKNESS FOR THE PURPOSE OF REDUCING ACTUATING SHEAR STRESS CONCENTRATION BY ANSYS
}

\author{
Nan LIU ${ }^{1}$, Hongping HU ${ }^{2, *}$ \\ ${ }^{1}$ Department of Mechanical and Materials Engineering, University of Nebraska-Lincoln, Lincoln, NE 68588-0526, USA \\ ${ }^{2}$ Department of Mechanics, Huazhong University of Science and Technology, Wuhan 430074, China \\ ${ }^{*}$ Corresponding author, E-mail: hphu@yahoo.cn; Tel.: 86-27-87559409.
}

\begin{abstract}
An elastic plate with thin piezoelectric films bonded on its two major surfaces is a typical smart structure which is used in actuation and sensing. The useful deformation of the smart structure is caused by the shear stress transferring from the actuators to the elastic plate. This shear stress is concentrated at two ends of the interface between the actuator and the plate. This concentration may induce undesirable delamination of the actuator from the plate. It was theoretically proved that actuators with partially covered electrodes have a much less concentrated actuating shear stress than that with fully ones. An actuator with nonuniform thickness was also found that may reduce the concentration of shear stress. The previous theoretical results were based on two simplified models. However, it is very difficult to get an analytical solution when the actuator owns the two characteristics at the same time, i.e. not only with partially covered electrodes, but also with an in-plane varied thickness. In this paper, we turn to use ANSYS to obtain useful numerical results from cases which are nearly impossible to be solved analytically. We study the effect of the electroded area of the actuator on reducing the concentrated shear stress. Moreover, we investigate the shear stress distribution under different variation of the actuator thickness. An optimal thickness profile is obtained. This work is considered as a frontier of smart structure.
\end{abstract}

Keywords: Piezoelectric; Actuator; ANSYS

\section{INTRODUCTION}

The interfacial shear stress between the piezoelectric film and elastic plate is induced by expanding or contraction of the piezoelectric film, also referred to as actuator. It was theoretically proved that this interfacial shear stress concentrates at two ends of actuator [1-4]. In fact, the concentration of shear stress always exists for a film on a substrate when the film expands or contracts due to different effects $[5,6]$. It was theoretically proved that ending the electrodes a short distance from the edge of actuator reduces the stress concentration $[1,2,4]$. It was also shown analytically that actuators with nonuniform thickness may also reduce the concentration of shear stress [7]. The above results were obtained based on simple models. It is very difficult to get an analytical solution when a more complicated model is employed. Finite element analyses of piezoelectric actuator on a substrate were reported in [8-11]. However, the effects of actuator thickness and partially covered electrodes on reducing the shear stress concentration have not been studied by finite element method.
It is an important criterion to measure an actuator which can produce a large displacement or deflection, but with a low concentrated stress. In this paper, we study the effect of increment or decrement of the electroded area of the actuator on reducing the concentrated shear stress by using ANSYS. We also investigate the shear stress distribution under different variation of the actuator thickness and an optimal profile of the actuator thickness is obtained.

\section{STRUCTURE AND MODEL}

For the purpose of investigating shear stress concentration, a 2D plane strain model is employed as shown in Fig. 1. A piezoelectric actuator is bonded on the upper surface of an elastic plate. The elastic plate is fixed at the left end. The actuator is far from the two ends of the elastic plate, thus the shear stress distribution under the actuator is not influenced by the boundary conditions at the two ends according to the Saint Venant's principle. The electrodes are deposited on the upper and lower

978-1-4673-1078-9/11/\$26.00 (C2011 IEEE 
surfaces of the actuator. The thicknesses of electrodes are much smaller than that of actuator, so the very small effect caused by the thickness and stiffness of electrodes is ignored in this model.

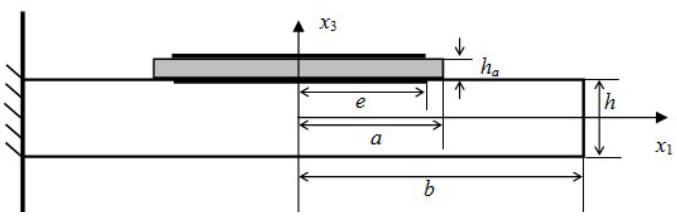

Figure 1. Uniform actuator

\section{NUMERICAL RESULTS AND DISCUSSION}

The actuator is made of piezoelectric ceramic PZT-5H which is poled in the thickness direction. The elastic plate is made of aluminum alloy 6061-T6. $1 \mathrm{~V}$ voltage is applied on the upper surface of the electrode, and the lower surface of the electrode is grounded. $a=5 \mathrm{~cm}, b=10$ $\mathrm{cm}, h=1 \mathrm{~cm}$. Quadrilateral element PLANE13 for coupled fields is used to mesh the actuator and quadrilateral PLANE182 is used to mesh the elastic plate. The element size is unified as $0.5 \mathrm{~mm}$ for all the following cases.

\subsection{Uniform thickness actuator}

First we investigate uniform thickness actuator with fully covered electrodes. The uniform thickness of actuator $h_{a}=2 \mathrm{~mm}, e=5 \mathrm{~cm}$. Figure 2 shows the distribution of shear stress $T_{31}$ along the interface between the actuator and the elastic plate $\left(x_{3}=h / 2\right)$. The maximum shear stresses $(3437 \mathrm{~Pa})$ occur at the two ends of the actuator. The maximum displacement of the plate is at the top right corner $(0.108 \mu \mathrm{m})$.

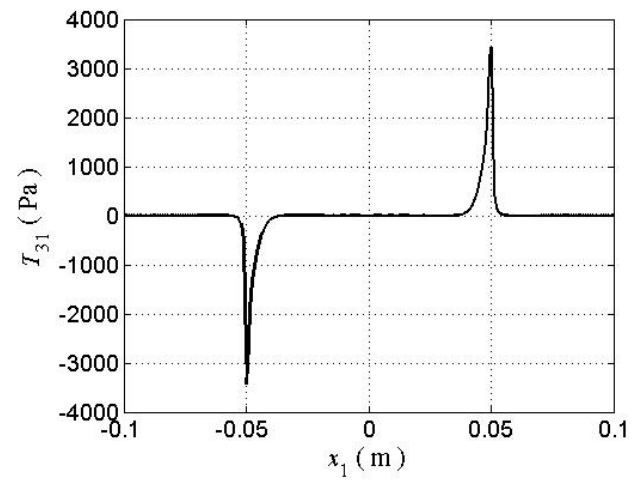

Figure 2. Shear stress distribution of uniform actuator with fully covered electrodes

If the same thickness actuator is partially covered with electrodes $(e=4 \mathrm{~cm})$, the distribution of shear stress $T_{31}$ is shown in Fig. 3. The concentration of stress at two ends is obviously reduced to $2661 \mathrm{~Pa}$ under the partially covered electrodes, as predicted in $[1,2,4]$.The maximum displacement at the top right corner is reduced to 0.0916 $\mu \mathrm{m}$. Figure 3 also shows that if the length of electrodes decreases to $e=3 \mathrm{~cm}$, the concentration of stress is not further reduced, but the maximum deflection drops to $0.069 \mu \mathrm{m}$.

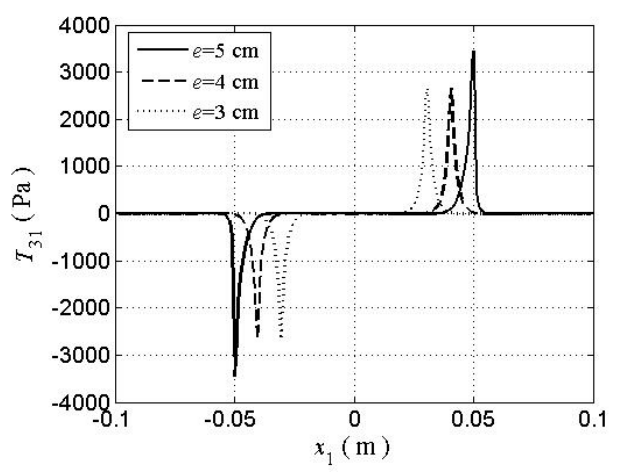

Figure 3. Shear stress distribution of uniform actuator with covered electrodes of different $e$

If the actuator is fully covered with $e=5 \mathrm{~cm}$, but with different $h_{a}$, the shear stress $T_{31}$ at the interface near the left end of the plate is shown in Fig. 4. The concentration of stress at two ends is reduced to $2489 \mathrm{~Pa}$ if $h_{a}$ increases from $2 \mathrm{~mm}$ to $3 \mathrm{~mm}$, but maximum displacement is also reduced to $0.0856 \mu \mathrm{m}$. The stress concentration is 1920 $\mathrm{Pa}$ if $h_{a}=4 \mathrm{~mm}$, and the maximum displacement further decreases to $0.069 \mu \mathrm{m}$. It is shown from Fig. 4 that shear stress concentration becomes smaller with increasing thickness, however the actuation capability of the actuator also decreases.

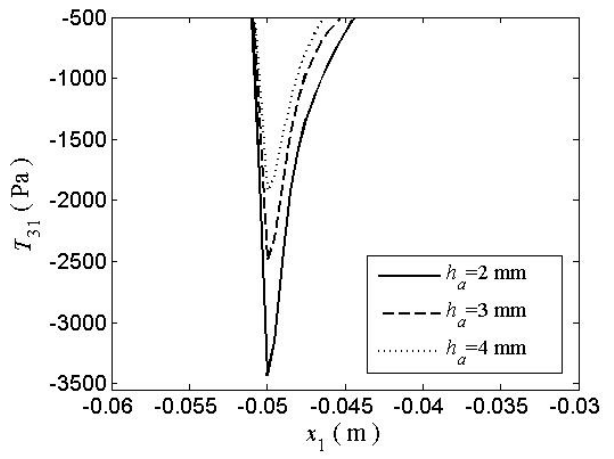

Figure 4. Shear stress distribution of uniform actuator with different thickness

\subsection{Nonuniform thickness actuator}

We next investigate the effect of nonuniform-thickness actuator on the stress concentration at two ends. Based on the theoretical conclusion that concentrated shear stress is reduced when the actuator is thicker near the edges [7], we build a model with step thickness as shown in Fig. 5. The edges of actuator are raised to two steps where $h_{a}=4 \mathrm{~mm}$. The middle thickness $h_{m}=2 \mathrm{~mm}$. It is 
observed from Fig. 3 that the width of shear stress concentration is about $2 \mathrm{~cm}$, so the stress concentration would be trapped in the two steps if $a_{m}=2 \mathrm{~cm}$, the rest dimensions remain unchanged. The distribution of shear stress $T_{31}$ at $x_{3}=h / 2$ is shown in Fig. 6.

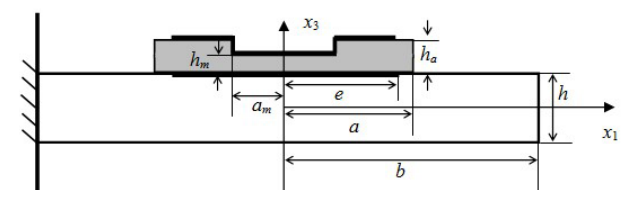

Figure 5. Actuator with step thickness

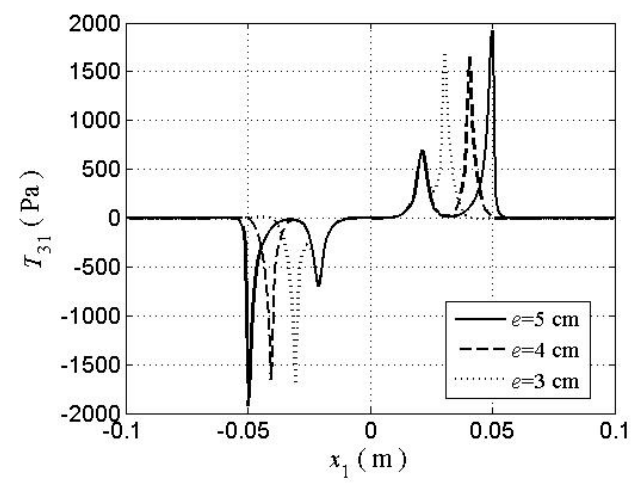

Figure 6. Shear stress distribution of step-thickness actuator with different $e$

If the actuator is fully covered with electrodes $e=5$ $\mathrm{cm}$, the concentration of stress at two ends is $1920 \mathrm{~Pa}$ (44\% of concentrated stress is reduced compared with uniform actuator with fully covered electrodes). The maximum displacement at the plate tip is $0.0856 \mu \mathrm{m}$ (79\% of that for fully covered uniform actuator). If the electrode is partially covered with $e=4 \mathrm{~cm}$, the maximum shear stress is $1645 \mathrm{~Pa}$ (38\% of concentrated stress is reduced compared with uniform actuator with $e=4 \mathrm{~mm}$ ), the maximum displacement is $0.0769 \mu \mathrm{m}(84 \%$ of that for uniform actuator with $e=4 \mathrm{~mm}$ ). If $e=3 \mathrm{~cm}$, the maximum shear stress is increased a little to $1671 \mathrm{~Pa}$, however, the maximum displacement is further reduced to $0.0620 \mu \mathrm{m}$.

We conclude that step-thickness actuator has smaller concentration at the two ends and at the same time it maintains the actuation capability at a certain level. However, further decreasing $e$ will not further reduce the stress concentration. The effect of partially covered electrodes on reducing the stress concentration has its limit. The above results are illustrated in Table 1. We also observe from Fig. 6 that there are small stress concentrations at $x_{1}= \pm a_{m}$ due to the sudden jump of actuator thickness.

Table 1. Concentrated stress $(\mathrm{Pa})$ and maximum displacement $(\mu \mathrm{m})$

Actuator $\quad e=5 \mathrm{~cm} \quad e=4 \mathrm{~cm} \quad e=3 \mathrm{~cm}$

\begin{tabular}{cccc}
\hline Uniform & 3437 & 2661 & 2661 \\
$\left(h_{a}=2 \mathrm{~mm}\right)$ & 0.108 & 0.0916 & 0.069 \\
Step-thickness & 1920 & 1645 & 1671 \\
& 0.0856 & 0.0769 & 0.0620 \\
Smooth concave & 1918 & 1645 & 1658 \\
& 0.0822 & 0.0734 & 0.0586 \\
\hline
\end{tabular}

We also investigate the effect of the width of the step. A step-thickness actuator with fully covered actuators but with different $a_{m}$ is shown in Fig. 7, if $a_{m}=3 \mathrm{~cm}$ the maximum shear stress is not reduced (1921 Pa), but the maximum displacement increases from 0.0856 to $0.0934 \mu \mathrm{m}$. If we further narrow the step width to $a_{m}=4 \mathrm{~cm}$, the maximum shear stress increases to 1973 $\mathrm{Pa}$, the maximum displacement increases to $0.101 \mu \mathrm{m}$. It is also shown that the stress concentration at $x_{1}= \pm$ $a_{m}$ is $559 \mathrm{~Pa}$ when $a_{m}=2$ or $3 \mathrm{~cm}$, but raised to $661 \mathrm{~Pa}$ when $a_{m}=4 \mathrm{~cm}$. It can be concluded from Fig. 7 that smaller step width has little effect on reducing the stress concentration, but obviously generates larger actuation capability.

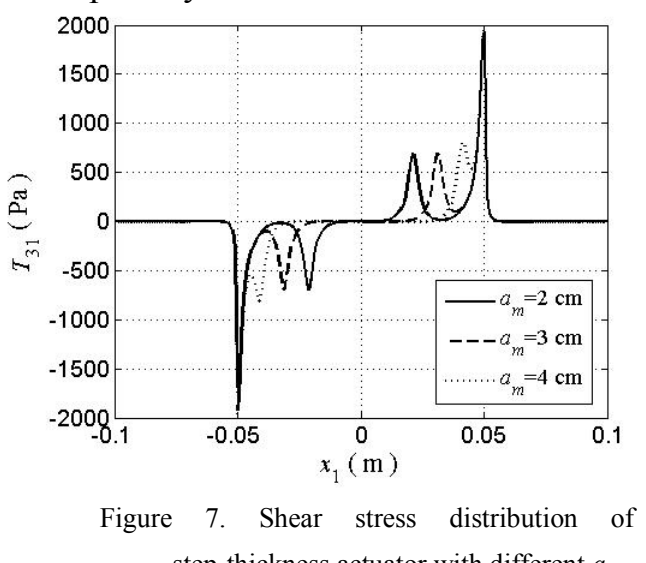

\subsubsection{Smooth concave actuator}

In order to reduce the stress concentration due to the sudden jump of actuator thickness, our next model includes a smooth concave actuator in Fig. 8 where $a_{r}=2$ $\mathrm{cm}, h_{m}=0.02 \mathrm{~mm}$, all the other dimensions remain unchanged. Result is shown in Fig. 9.

For the effect of electroded area on reducing shear stress concentration, the current model has very similar result as shown by the step-thickness actuator. If the electrode is fully covered $e=5 \mathrm{~cm}$, the concentration of

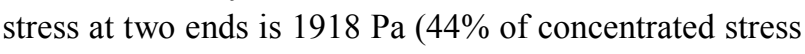
is reduced compared with uniform actuator with fully covered electrodes), maximum displacement at the plate tip is $0.0822 \mu \mathrm{m}(76 \%$ is maintained). If the electrode is partially covered with $e=4 \mathrm{~cm}$, the maximum shear stress is $1645 \mathrm{~Pa}(38 \%$ of concentrated stress is reduced compared with uniform actuator with $e=4 \mathrm{~mm}$ ), the 
maximum displacement also reduces a little to 0.0734 $\mu \mathrm{m}$ ( $80 \%$ is maintained). If $e=3 \mathrm{~cm}$, the maximum shear stress is no more reduced, but increased a little to 1658 $\mathrm{Pa}$, the maximum displacement becomes $0.0586 \mu \mathrm{m}$. The above results are also illustrated in Table 1 . However, the advantage of current model over the step-thickness actuator is that the small stress concentrations at $x_{1}= \pm a_{r}$ are reduced significantly from $556 \mathrm{~Pa}$ in Fig. 6 of previous case to $279 \mathrm{~Pa}$ in current smooth-thickness case, nearly $50 \%$ of stress is reduced.

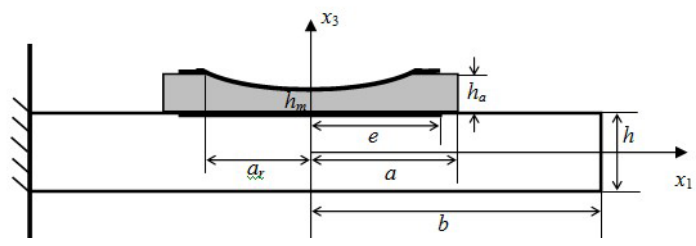

Figure 8. Smooth concave actuator

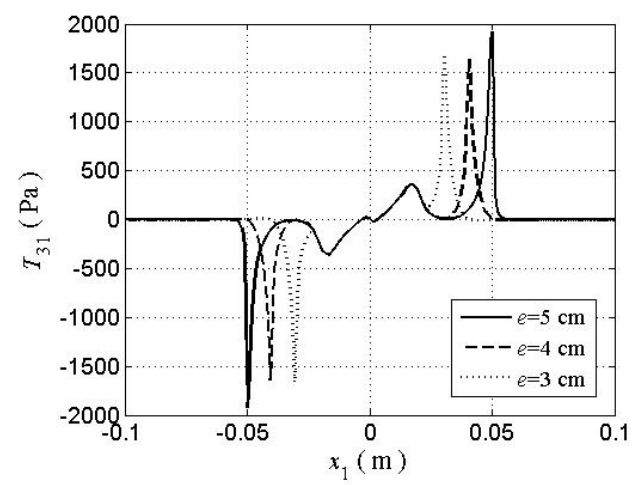

Figure 9. Shear stress distribution of smooth concave actuator with different $e$

\section{CONCLUSION}

By performing numerical experiments using ANSYS, we confirm that partially covered electrodes reduces the concentrated shear stress, but further decrement of electrode area would not reduce the concentration any more. The effect of partially covered electrodes on reducing the stress concentration has its limit.

We also investigate the shear stress distribution under step-thickness and smooth concave actuators. Smooth concave actuators generate less stress concentrations and meanwhile still maintain certain level of actuation capacity.

\section{AKNOWLEDGEMENT}

This work was supported by the National Science Foundation of China (Nos. 10872074 and 10932004),
Major State Basic Research Development Program of China (973 Program) (No. 2009CB724205), and Fundamental Research Funds for the Central Universities (No. 2011QN184). The authors wish to thank Professor Jiashi Yang of University of Nebraska-Lincoln for suggesting this study.

\section{REFERENCES}

[1] Tiersten HF. Equations for the control of the flexural vibrations of composite plates by partially electroded piezoelectric actuators. In: SPIE Proc., vol. 2427, pp. 326-342, 1994.

[2] Yang JS, Tiersten HF. Elastic analysis of the transfer of shearing stress from partially electroded piezoelectric actuators to composite plates in cylindrical bending. Smart Mater. Struct. 6(3): 333-340, 1997.

[3] Seemann WE. Stresses in a thin piezoelectric element bonded to a half-space. Appl. Mech. Rev. 50(11S): S204-209, 1997.

[4] Liu YJ, Fan H, Yang JS. Analysis of the shear stress transferred from a partially electroded piezoelectric actuator to an elastic substrate. Smart Mater. Struct. 9(2): 248-254, 2000.

[5] Hu SM. Film-edge-induced stress in substrates. J. Appl. Phys. 50(7): 4661-4666, 1979.

[6] Lau JH. Thermoelastic solutions for a semi-infinite substrate with a powered electronic device. J. Electron. Packag. 114(3): 353-358, 1992.

[7] Yang ZT, Hu YT, Yang JS. Thin film piezoelectric actuators with nonuniform thickness for reducing actuating shear stress concentration. J. Intell. Mater. Syst. Struct. 20(6): 729-731, 2009.

[8] Huang GL, Song F, Wang XD. Quantitative modeling of coupled piezo-elastodynamic behavior of piezoelectric actuators bonded to an elastic medium for structural health monitoring: a review. Sensors 10(4): 3681-3702, 2010.

[9] Yang JS, Xue H, Hu YT, Finite element analysis of stress field concentration near the edge of an electrode. Ferroelectr. Lett. Sect. 34(3): 108-111, 2007.

[10] Cui QF, Liu CL, Zha XF, Modeling and numerical analysis of a circular piezoelectric actuator for valveless micropumps. J. Intell. Mater. Syst. Struct. 19(10): 1195-1205, 2008.

[11] Glcm DA, Ribeiro JF, Steffen VJ, Finite element modeling of a plate with localized piezoelectric sensors and actuators, J. Braz. Soc. Mech. Sci. Eng. 26(2): 117-128, 2004. 